\title{
Open ocean dead zones in the tropical North Atlantic Ocean
}

\author{
J. Karstensen ${ }^{1}$, B. Fiedler ${ }^{1}$, F. Schütte ${ }^{1}$, P. Brandt ${ }^{1}$, A. Körtzinger ${ }^{1}$, G. Fischer ${ }^{2}$, R. Zantopp ${ }^{1}$, J. Hahn ${ }^{1}$, M. Visbeck ${ }^{1}$, \\ and D. Wallace ${ }^{3}$ \\ ${ }^{1}$ GEOMAR Helmholtz Centre for Ocean Research Kiel, Kiel, Germany \\ ${ }^{2}$ Faculty of Geosciences and MARUM, University of Bremen, Bremen, Germany \\ ${ }^{3}$ Halifax Marine Research Institute (HMRI), Halifax, Canada
}

Correspondence to: J. Karstensen (jkarstensen@geomar.de)

Received: 3 November 2014 - Published in Biogeosciences Discuss.: 12 December 2014

Revised: 27 February 2015 - Accepted: 1 April 2015 - Published: 30 April 2015

\begin{abstract}
Here we present first observations, from instrumentation installed on moorings and a float, of unexpectedly low $\left(<2 \mu \mathrm{mol} \mathrm{kg}{ }^{-1}\right)$ oxygen environments in the open waters of the tropical North Atlantic, a region where oxygen concentration does normally not fall much below $40 \mu \mathrm{mol} \mathrm{kg}^{-1}$. The low-oxygen zones are created at shallow depth, just below the mixed layer, in the euphotic zone of cyclonic eddies and anticyclonic-modewater eddies. Both types of eddies are prone to high surface productivity. Net respiration rates for the eddies are found to be 3 to 5 times higher when compared with surrounding waters. Oxygen is lowest in the centre of the eddies, in a depth range where the swirl velocity, defining the transition between eddy and surroundings, has its maximum. It is assumed that the strong velocity at the outer rim of the eddies hampers the transport of properties across the eddies boundary and as such isolates their cores. This is supported by a remarkably stable hydrographic structure of the eddies core over periods of several months. The eddies propagate westward, at about 4 to $5 \mathrm{~km}_{\text {day }}{ }^{-1}$, from their generation region off the West African coast into the open ocean. High productivity and accompanying respiration, paired with sluggish exchange across the eddy boundary, create the "dead zone" inside the eddies, so far only reported for coastal areas or lakes. We observe a direct impact of the open ocean dead zones on the marine ecosystem as such that the diurnal vertical migration of zooplankton is suppressed inside the eddies.
\end{abstract}

\section{Introduction}

The concentration of dissolved oxygen (DO) in seawater is of critical importance to almost all marine life and oceanic biogeochemical cycling (Wilding, 1939; Diaz and Rosenberg, 2008; Vaquer-Sunyer and Duarte, 2008; Wright et al., 2012; Kalvelage et al., 2011). Local DO concentrations are the result of a delicate balance between oxygen supply and consumption, and eventually regions of extremely low DO content are created: at the microscale at particle boundaries (Alldredge and Cohen, 1987), at the mesoscale as coastal dead zones (Diaz and Rosenberg, 2008) or at the large scale as eastern boundary oxygen minimum zones (OMZs) (Luyten et al., 1983; Karstensen et al., 2008; Brandt et al., 2015). Quantifying and fully understanding processes that control the DO supply and consumption balance, and any possible alterations over time, remain challenges in current research.

Critical DO concentration thresholds which lead to major reorganizations of the marine ecosystems have been identified (Vaquer-Sunyer and Duarte, 2008; Wright et al., 2012; Kalvelage et al., 2011). For higher trophic levels, such as those of fish, the impact of a certain DO level on metabolism, and as such fitness, is species-dependent (Wilding, 1939). Nevertheless, for DO below $20 \mu \mathrm{mol} \mathrm{kg}^{-1}$ ("severe hypoxia"), mass mortality of fish has been reported (Diaz and Rosenberg, 2008). At severe hypoxia DO levels, microbes begin to convert nitrite and ammonium to nitrogen gas, thus removing fixed nitrogen from the water, which in turn limits primary productivity (Wright et al., 2012; Kalvelage et al., 2011). A next distinct DO threshold is for concentrations below about $5 \mu \mathrm{mol} \mathrm{kg}{ }^{-1}$, where microbes begin to utilize nitrate (and other nitrogen species) as terminal 


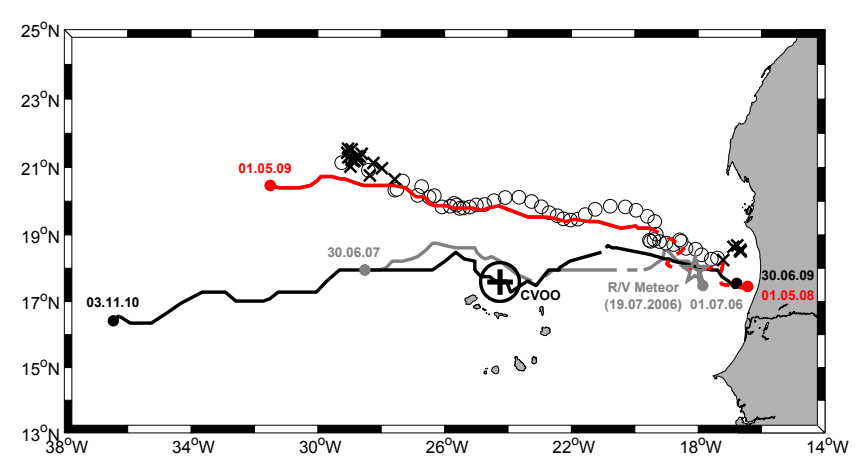

Figure 1. Overview map of the eastern tropical North Atlantic oxygen minimum zone. The tracks of the two anticyclonic-modewater eddies (CVOO2007, grey line; CVOO2010, black line) observed at CVOO (plus sign; $17^{\circ} 35.39^{\prime} \mathrm{N}, 24^{\circ} 15.12^{\prime} \mathrm{W}$ ) as well as the track of the cyclonic eddy (Argo2008, red line), surveyed with an Argo float are shown. The position (dots) and dates (label) of the first and last identification of the three eddies are given. The RV $M E$ TEOR survey of the CVOO2007 (grey star) is labelled accordingly. For reference, the average footprint (circle at CVOO) is given. Positions of the Argo float profiles surveyed inside (white circles) as well as outside the cyclonic eddy radius (crosses) are shown.

electron acceptors in anaerobic respiration ("denitrification") (Wright et al., 2012; Kalvelage et al., 2011). Finally, when DO reach concentrations around $1 \mu \mathrm{mol} \mathrm{kg}^{-1}$ ("anoxia"), only specifically adapted microbes can exist (Wright et al., 2012).

The pelagic zones of the eastern tropical North Atlantic OMZ are considered to be "hypoxic", with minimal DO of marginally below $40 \mu \mathrm{mol} \mathrm{kg}^{-1}$ (Stramma et al., 2009; Karstensen et al., 2008). As such it is assumed that the DO levels pose some limitation in biodiversity on the regional ecosystem, primarily through avoidance and possibly increased mortality (Vaquer-Sunyer and Duarte, 2008). The region is thus very much in contrast to the major OMZs in the eastern North and South Pacific Ocean and the northern Indian Ocean, where DO concentrations pass all DO thresholds outlined above, and as such specifically adapted ecosystems must exist.

Here the discovery of extremely low DO in mesoscale eddies in the eastern tropical North Atlantic is documented. The DO values fall in the range of severe hypoxia and even anoxia. They extend over horizontal scales of about $100 \mathrm{~km}$ and vertical scales of about $100 \mathrm{~m}$.

\section{Data and methods}

\subsection{Moored sensors}

One set of DO time series we discuss below was acquired at the Cape Verde Ocean Observatory (CVOO) mooring. $\mathrm{CVOO}$ is located in the eastern tropical North Atlantic, about $100 \mathrm{~km}$ northeast of the São Vicente $\left(17^{\circ} 35^{\prime} \mathrm{N}, 24^{\circ} 15^{\prime} \mathrm{W}\right)$,
Cabo Verde, and approximately $800 \mathrm{~km}$ from the Mauritanian coast (Fig. 1). Since 2006 the observatory has been equipped with oxygen sensors: first only one sensor was installed at about $140 \mathrm{~m}$ depth, but since the beginning of 2008 at least two sensors have been installed, one of which measuring at depths shallower than $60 \mathrm{~m}$.

The oxygen measurements at the CVOO mooring were done with AADI Aanderaa oxygen optode (type 3830) sensors. For the first two deployments (period from July 2006 to October 2009) we followed the recommendation of the manufacturer and performed a calibration against zero oxygen concentration, by submerging the optodes in a sodium sulfite solution, and against saturated waters. For the following periods a more advanced technique was used, based on a number of calibration points at different temperatures and oxygen concentrations (Hahn et al., 2014). In brief, one set of calibration values was obtained from a comparison of oxygen data from an optode attached to a CTD rosette and the accompanying CTD oxygen sensor (Sea-Bird Electronics 43 Clark electrode) calibrated itself using the Winkler titration method. This comparison was done by keeping the CTD over several minutes at a certain depth where a weak vertical oxygen gradient was seen. This procedure was done before and after the deployment of the respective optodes. In this way we obtained $>15$ independent calibration points for each optode. In addition, a lab calibration at zero oxygen was done. All calibration points were used to derive a final calibration equation for one deployment of one certain optode. The chemically forced (and thus more precise) zero oxygen calibration was weighted 3 times higher than the CTD/oxygen cast reference values. The difference between calibration point observations and calibrated optode suggests an overall RMSE of $3 \mu \mathrm{mol} \mathrm{kg}{ }^{-1}$. Comparison of the chemically forced zero oxygen phase data and the phase readings at low-oxygen concentrations suggests a higher accuracy at low DO concentrations of about $1 \mu \mathrm{mol} \mathrm{kg}{ }^{-1}$. Pressure and salinity variability was corrected according to the AADI manual.

\subsection{Argo float data}

A profiling float was launched in the tropical North Atlantic region to document the seasonal variability in upper layer DO and particle load. By accident it was entrained into the lowoxygen eddy. The float was a PROVOR profiling Argo float (WMO 6900632; Martec Inc., France) equipped with a standard CTD (SBE 41CP), an oxygen optode (AADI Aanderaa optode 3830) and a transmissometer (CRV5, WETLabs). The float was programmed to conduct a vertical profile every 5 th day between $400 \mathrm{dbar}$ (nominal drift depth) and the surface with a vertical resolution of $5 \mathrm{dbar}$ throughout the profile. The DO concentrations obtained from the float were corrected for salinity effects (using the float CTD salinity) and a pressure correction was applied to the data (Tengberg et al., 2006), increasing the oxygen linearly by $4 \%$ per 100 bar. 
Moreover, we had one in situ calibration CTD calibration cast available, recorded a few hours after deployment of the float. The CTD oxygen sensor (Sea-Bird Electronics 43 Clark electrode) was again calibrated using the Winkler titration method. This procedure resulted in a post-offset correction of float-based DO measurements. The transmissometer data were not further calibrated and are reported here in units of $\mathrm{m}^{-1}$ (beam attenuation coefficient) based on the factory calibration. The sensor data are presumably impacted by bio-fouling within the optical path, and this was accounted for by subtracting the minimum deep water beam attenuation value from each profile.

\subsection{Satellite data and eddy tracking}

The delayed time reference product of merged sealevel anomaly (SLA) data (version 2010) provided by AVISO (Archiving, Validation, and Interpretation of Satellite Oceanographic) was used for tracking of the three eddies under discussion. The SSALTO/DUACS project constructs a merged satellite product projected on a $1 / 3^{\circ}$ horizontal resolution Mercator grid every 7 days (e.g. Pascual et al., 2006, and references therein).

Initially we tracked the three eddies under discussion visually by inspecting individual SLA maps. This was possible as we knew the exact time and location of the appearance of low-DO eddies from the in situ observations (mooring, float). By looking up subsequent SLA maps, the displacement of an identified SLA that was associated with the three eddies was charted and eddy tracks were constructed for the period before and after the in situ observation (Fig. 1).

However, in addition we used an automatic detecting and tracking algorithm, based on the Okubo-Weiß method (Okubo, 1970). The method is robust and widely used to detect mesoscale eddies in satellite data as well as numerical model output (Chelton et al., 2007; Sangrà et al., 2009; Souza et al., 2011). In brief, the method is based on quantifying the contribution of relative vorticity on the strain tensor, and an eddy is defined as a region of negative $W$ (vorticity dominates over strain) surrounded by a region of positive $W$ (strain dominates over vorticity). A threshold $W_{0}$ has to be chosen, and we used $W_{0}=-2 \times 10^{-12} \mathrm{~s}^{-2}$ for our eddy detection limit. Tracking was done by following the centre of individual $W_{0}$ areas in SLA maps from 1 (maximum $10 \mathrm{~km}$ ) to 3 weeks (maximum distance $60 \mathrm{~km}$ ). The automatic detection reproduced well the tracking that was obtained using the visual inspection method.

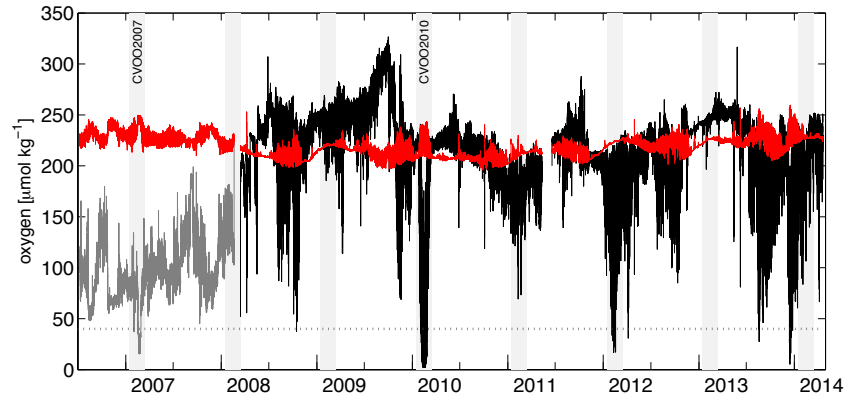

Figure 2. Time series of DO from the CVOO site at 40 to $60 \mathrm{~m}$ depth (black line) and at $140 \mathrm{~m}$ (grey line) during the beginning of the time series. The passage of the two anticyclonic-modewater eddies in February 2007 (CVOO2007) and February 2010 (CVOO2010) is labelled accordingly. The theoretical oxygen surface saturation (red line) is shown, as well as the $40 \mu \mathrm{mol} \mathrm{kg}{ }^{-1}$ threshold reported in the literature. The period from 15 January to 15 March for each year is indicated by grey-shaded area.

\section{Results and discussion}

\subsection{Open ocean low-oxygen events from moored observation}

Anomalously low DO, in reference to the expected lower limit for the tropical North Atlantic of about $40 \mu \mathrm{mol} \mathrm{kg}{ }^{-1}$ (Stramma et al., 2009), was first identified in the DO time series available from the CVOO mooring (Fig. 2). At the CVOO mooring the typical DO concentrations in the upper $60 \mathrm{~m}$ are close to the oxygen saturation value (> $200 \mu \mathrm{mol} \mathrm{kg}{ }^{-1}$; Garcia and Gordon, 1992), with variability of about $50 \mu \mathrm{mol} \mathrm{kg}^{-1}$ over periods of a few days or so. However, exceptionally low DO events were observed during boreal winters of 2007, 2010, 2011 and 2012. In the following we concentrate on the two most extreme low-DO events in 2007 and 2010.

The most intense low-DO event was recorded in February 2010 (CVOO2010, Fig. 3a) at the mooring site and persisted over a period of about 1 month. During that period, DO concentrations at shallow depth $(42 \mathrm{~m})$ were $<2 \mu \mathrm{mol} \mathrm{kg}^{-1}$ and thus close to the DO threshold for anoxia. A second sensor, installed deeper, at a nominal $170 \mathrm{~m}$, also showed a drastic DO decrease from the typical $100 \mu \mathrm{mol} \mathrm{kg}^{-1}$ to less than $30 \mu \mathrm{mol} \mathrm{kg}{ }^{-1}$ during the event. Inspecting the hydrography and currents, recorded with multiple other moored instruments, we observed that the low-DO event was accompanied by the appearance of a lens of cold and less saline water (Fig. 3c, d) and a strong and reversing meridional flow (Fig. 3b). The flow reversal (from a northward flow to a southward flow) indicates the passage of an anticyclonic eddy across the mooring.

Further inspection of the temporal evolution of isopycnals (surfaces of constant water density) during the eddy passage 
a

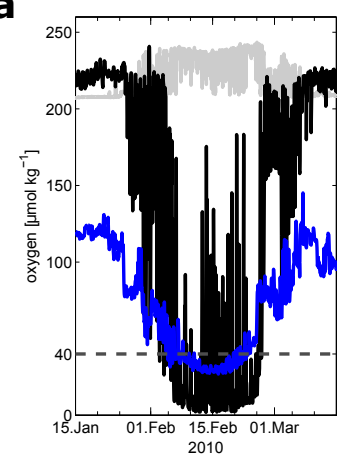

C

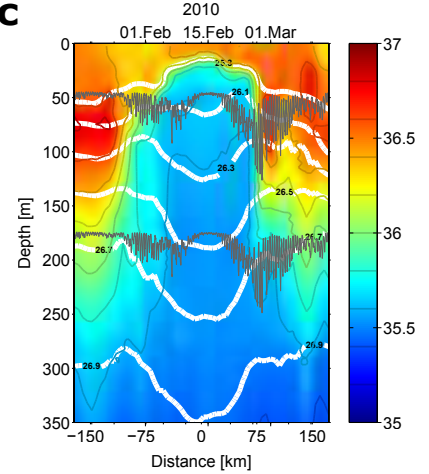

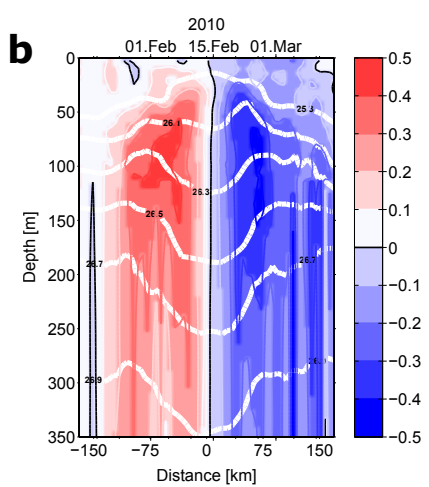

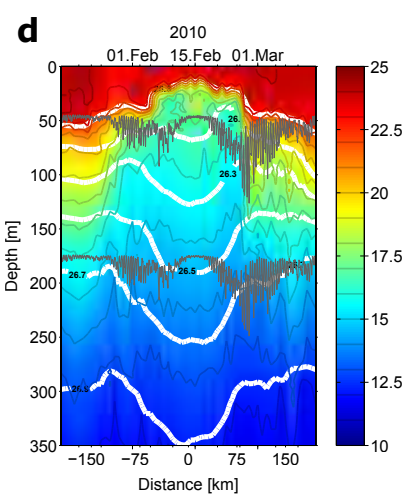

Figure 3. (a) Time series of DO from the two sensors available at nominal $42 \mathrm{~m}$ (black line) and $170 \mathrm{~m}$ depth (blue line). For reference, the oxygen surface saturation (grey line) and the $40 \mu \mathrm{mol} \mathrm{kg}-1$ threshold (black broken line) are shown. Corresponding time series of (b) meridional flow $\left(\mathrm{m} \mathrm{s}^{-1}\right)$, (c) salinity (in PSS-78), and (d) potential temperature $\left({ }^{\circ} \mathrm{C}\right)$ in the upper $350 \mathrm{~m}$ as observed during the CVOO2010 passage are shown. The black line in (b) indicates zero meridional velocity, and the grey lines in (c) and (d) indicate the varying depth of the oxygen sensors shown in (a) during instalment. Selected potential density anomaly surfaces are shown as white contours in (b), (c) and (d) for reference, and the time series data were converted into distance assuming an eddy translation speed of $5 \mathrm{~km}$ day $^{-1}$.

indicated that a special type of anticyclonic eddy, a so-called anticyclonic-modewater or intrathermocline eddy (Kostianoy and Belkin, 1989; McGillicuddy et al., 2007), crossed the mooring. Anticyclonic-modewater eddies can be identified from downward/upward-bent isopycnals towards the eddy centre below/above a subsurface swirl velocity maximum. The transition between upward- and downward-bent isopycnals forms a lens (or mode) of a specific water mass which can be at all water depths. Prominent examples of intrathermocline eddies are so-called "meddies", which propagate at depths between 500 and $1500 \mathrm{~m}$ and have been formed from instabilities of the Mediterranean outflow after entering the North Atlantic through the Strait of Gibraltar (Armi and Zenk, 1984). In our observations the mode is at much shallower depth, centred at about $70 \mathrm{~m}$, and had a height of about $50 \mathrm{~m}$ or so. It contained the most extreme low DO concen-

a

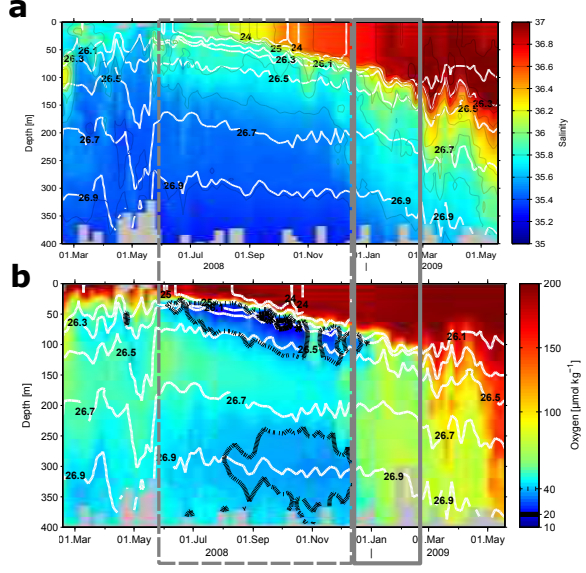

c

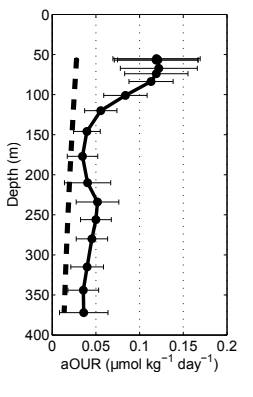

Figure 4. Time series of (a) salinity and (b) oxygen from profiling float data. The two grey boxes indicate the period when the float was trapped in the cyclonic eddy; these represent the isolated period (dashed box, left) and the non-isolated period (solid box, right). Potential density anomaly contours are shown as contour lines. (c) Vertical profile of the aOUR derived from successive dives during the period when the eddy was isolated. The thick broken line shows the background aOUR (Karstensen et al., 2008).

trations. Below this mode, the eddy had a structure of a typical anticyclone and reached deeper than $1400 \mathrm{~m}$ (not shown). Along with the passage of the CVOO2010 eddy, the surface mixed layer shoaled from a thickness of about $50-60 \mathrm{~m}$ before (and after) the eddy passage to less than $20 \mathrm{~m}$ during the eddy passage.

Another extreme event in the DO record from the CVOO mooring time series (Fig. 2) is seen in February 2007 (CVOO2007), almost exactly 3 years before the 2010 event. Again the low-DO event was accompanied by a flow reversal and hydrographic anomalies as seen during CVOO2010; as such it was associated with the passage of an anticyclonicmodewater eddy. At that time only a single oxygen sensor was installed at the CVOO mooring at $120 \mathrm{~m}$ depth (nominal), and the lowest DO concentrations were about $15 \mu \mathrm{mol} \mathrm{kg}{ }^{-1}$, indicating severe hypoxia $\left(20 \mu \mathrm{mol} \mathrm{kg}{ }^{-1}\right)$ conditions at the given depth.

\subsection{Open ocean low-oxygen events from Argo float data}

One further severe hypoxia event was detected within a cyclonic eddy that was surveyed with an Argo type float (Fig. 4a and b). The float was operating from midFebruary 2008 until the end of May 2009. Launched in the Mauritanian upwelling region, the float remained in the coastal area until the end of May 2008, when it began to move in a west-northwest direction into open waters (Fig. 1). Overlayed on the west-northwest movement, the float trajectory revealed "loops", which indicate rotational movement of a drifter, and the direction of rotation indicated a movement in a cyclonic eddy. 
With the westward propagation, into the open ocean waters, a decrease in DO at all depth levels below the mixed layer is observed. The decrease in DO lasted until mid-December 2008, and lowest DO concentrations (about $14 \mu \mathrm{mol} \mathrm{kg}{ }^{-1}$ ) were always found close to the mixed-layer base, which, however, successively deepened. After December 2008 the DO rather abruptly increased again (Fig. 4b), accompanied by drastic changes in temperature (not shown here) and salinity (Fig. 4a). However, from the eddy trajectory analysis presented below, it turned out that the float was still inside the eddy at the time of the abruptly changing interior structure.

\subsection{Propagation of oxygen anomalies}

The in situ data (CVOO2007, Argo2008, CVOO2010) provided us time periods and positions of low-DO events. Therefore it was simple to identify associated mesoscale eddies in SLA maps. The SLA maps revealed what was already seen from the hydrography - the two eddies observed at CVOO were anticyclonic eddies (the modewater character cannot be identified from the SLA data), and the Argo float surveyed a cyclonic eddy. Considering the along-path characteristics from concurrent SLA maps, all three eddies had roughly similar diameters (about $130 \mathrm{~km}$ ) and propagated westward, with a speed of about $4.5 \mathrm{~km} \mathrm{day}^{-1}$. As such they can be categorized as "typical" for this latitude range (Chelton et al., 2011b; Chaigneau et al., 2009). All three eddies had a similar region of origin at about $18^{\circ} \mathrm{N}, 16.5^{\circ} \mathrm{W}$. The cyclone was formed in May 2008 (the float entered the eddy core about 1 month later), and the two anticyclonic-modewater eddies in July 2006 and 2009, respectively.

The SLA across the eddy radius was rather weak, with an amplitude of only $1.5( \pm 1.5) \mathrm{cm}$ (negative for the cyclone, positive for the anticyclones). Such a SLA translates into maximum geostrophic surface currents of about 0.05 $0.10 \mathrm{~m} \mathrm{~s}^{-1}$, which is slow when compared with global eddy characteristics (Chelton et al., 2011b; Risien and Chelton, 2008). However, this is not too much of a surprise, as we knew, at least for the CVOO2007 and CVOO2010 eddies, from the in situ velocity data that the maximum velocity was at the subsurface, at about $70 \mathrm{~m}$ depth, and velocity rapidly decreased towards the surface (Fig. 3b). Thus the maximum in SLA-derived surface geostrophic flow is only $10-20 \%$ of the interior maximal swirl velocity directly observed with an acoustic Doppler current profiler (ADCP). We also used the density field derived from moored sensors and calculated a geostrophic velocity under the assumption that there is a layer with no motion at $1400 \mathrm{~m}$. This approach resampled the velocity structure fairly well and in particular the subsurface swirl velocity maximum at about $70 \mathrm{~m}$ depth. a

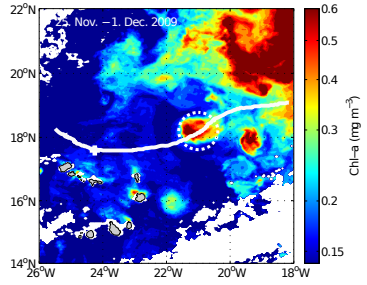

b

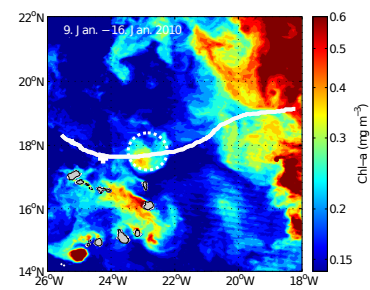

Figure 5. Surface chlorophyll concentration of the CVOO2010 anticyclone at two life stages approximately 2 months (a) and 1 month (b) before the centre of the anticyclone crossed the $\mathrm{CVOO}$ mooring. The SLA-derived track of the anticyclone centre (see Fig. 1) and the approximate diameter $(130 \mathrm{~km})$ are shown for reference. The white plus sign marks the CVOO position.

\subsection{Respiration in isolated eddies}

Various physical and biogeochemical processes have been identified as possible drivers of the ecosystem responses in mesoscale eddies. In particular, intense phytoplankton blooms have been reported for cyclonic and anticyclonicmodewater eddies (Mahadevan et al., 2008; McGillicuddy et al., 2007; Chelton et al., 2011a; Gaube et al., 2014). Phytoplankton blooms are likely important for creating a low-DO zone, because subsequent sinking of detritus is accompanied by oxygen consumption. Satellite-derived surface chlorophyll images would help to at least identify strong nearsurface bloom events in the three eddies, but cloud-free periods are rare in the region. However, the few available images with sufficient coverage (Fig. 5) show high chlorophyll fluorescence signals related to the eddies and suggest phytoplankton blooms to occur.

From the difference in DO concentrations between concurrent Argo float profiles we were able to estimate a depthdependent respiration rate (Fig. 4c) or apparent oxygen utilization rate (aOUR) profile. Only profiles where DO decreased (May to mid-December 2008) were considered. In order to take the successive deepening of isopycnals over time into account (e.g. Fig. 4a, contours), the aOUR was calculated in density classes and subsequently projected back to depth, using the mean vertical density profile.

The aOUR is highest, more than $0.15 \mu \mathrm{mol} \mathrm{kg}^{-1} \mathrm{day}^{-1}$, just below the mixed layer and levels out to about $0.05 \mu \mathrm{mol} \mathrm{kg}^{-1} \mathrm{day}^{-1}$ between $120 \mathrm{~m}$ and the maximum depth the float surveyed $(400 \mathrm{~m})$. The rates are 3 to 5 times higher than typical rates for the thermocline (Jenkins, 1982; Karstensen et al., 2008). Moreover, the rates must be seen as a lower bound of the real respiration inside of the eddy, as we assume no supply of DO by vertical mixing or from outside the eddy. Nevertheless, remarkable constant hydrography of the eddy core over time (Fig. 4b for temperature) suggests that lateral exchange across the eddy rim with surrounding waters is small. A connection between sinking particles and 
oxygen respiration is also seen in the transmissometer data (not shown). The transmissometer signal is at maximum just at the base of the mixed layer, while minimal DO is observed about $5 \mathrm{~m}$ below that particle maximum, indicating that the net oxygen respiration is related to sinking particles.

For the anticyclonic-modewater eddies a net DO respiration can only be derived for the CVOO2007 eddy and for one depth only. This is because the eddy was surveyed only twice during its lifetime: once by RV METEOR off Mauritania (Fig. 6), and 7 months later from the moored sensors at the CVOO mooring. Between these two surveys the DO concentrations at the $120 \mathrm{~m}$ depth (only depth with DO instrument at CVOO2007) changed by more than $50 \mu \mathrm{mol} \mathrm{kg}{ }^{-1}$, which translate into an aOUR of $0.25 \mu \mathrm{mol} \mathrm{kg} \mathrm{kday}^{-1}$. This is an even higher aOUR when compared with the aOUR profile derived from the cyclonic eddy at a corresponding depth, which might be related to a higher productivity (and subsequently oxygen drawdown through sinking particles) reported for anticyclonic-modewater eddies in the past (McGillicuddy et al., 2007). Moreover, comparison of the ship data from July 2006 and the mooring data from February 2007 (CVOO2007) reveals that the core of the eddy remained rather unchanged in temperature and salinity over a period of 7 months (Fig. 6), as well as after propagating more than $650 \mathrm{~km}$ westward.

A key process in the context of productivity is the vertical transport of nutrients into the euphotic zone. Different processes, operating on the sub-mesoscale, have been identified as being responsible for intense vertical velocities within eddies. However, the exact details are a topic that has been under debate for more than a decade (see Klein and Lapeyre, 2009; Lévy et al., 2012; Gaube et al., 2014; Pascual et al., 2015, for further references). Also, the trapping of surface waters by eddies should play a role (d'Ovidio et al., 2013). The data at hand do not allow for conclusions to be made on nutrient pathways within eddies, nor can we estimate productivity. However, a bulk estimate for the vertical velocity across the eddies can be done, making use of an approach based on wind stress variations generated by wind/surface current shear (Martin and Richards, 2001; McGillicuddy et al., 2007; Pascual et al., 2015). In brief, on one side of the eddy, where the wind blows against the eddy rotation, the wind stress is elevated while the contrary happens on the opposite side. The resulting wind stress curl drives an Ekman flux divergence, which in turn is compensated for by an upwelling in the case of anticyclonic surface eddy rotation (McGillicuddy et al., 2007). Using typical wind (10 $\mathrm{m} \mathrm{s}^{-1}$ ) and current speed $\left(0.5 \mathrm{~m} \mathrm{~s}^{-1}\right)$ across an eddy with a diameter of $130 \mathrm{~km}$ (as observed for the CVOO2010 and CVOO2007 eddy), we estimate an upwelling of about $9 \mathrm{~m} \mathrm{month}^{-1}$, corresponding to $65 \mathrm{~m}$ over the 7 months - the time it takes the eddies to propagate from the formation region, off West Africa, to the CVOO site. However, controversy exists regarding the validity of this concept (Mahadevan et al., 2008; Eden and Dietze, 2009).
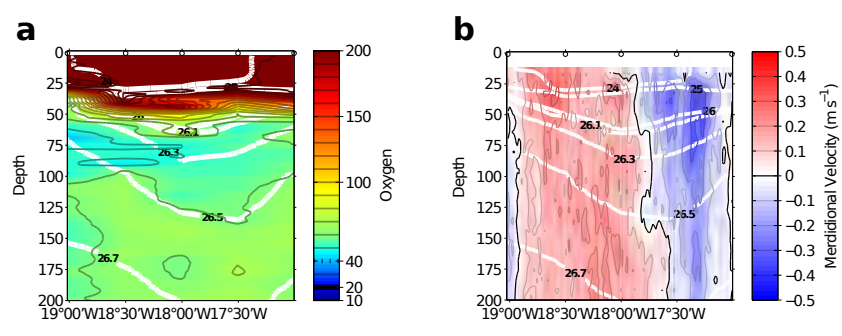

C

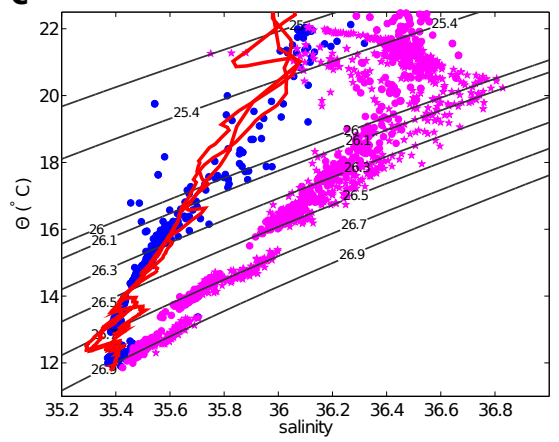

Figure 6. Vertical distribution of (a) oxygen $(\mu \mathrm{mol} \mathrm{kg}-1)$ and (b) meridional velocity $\left(\mathrm{m} \mathrm{s}^{-1}\right)$ surveyed with RV METEOR (cruise $\mathrm{M} 68 / 3$ ) on the 18 July 2006 , at $18^{\circ} \mathrm{N}$ and from 17 to $19^{\circ} \mathrm{W}$ (see Fig. 1 for position). (c) Hydrographic characteristics of the eddy core as observed with RV METEOR (red lines) and as observed 7 months later during the CVOO2007 passage (blue dots). For reference typical background conditions at CVOO are shown (magenta dots and stars).

Besides productivity, and the related sinking of detritus, the "isolation" of the eddy core from surrounding waters will also contribute to an increased net respiration. A clear indication of minimal exchange was seen in the constancy of the hydrographic structure of the eddy core, comparing properties of the eddy during the RV METEOR survey and from CVOO2007 (Fig. 6), as well as during the Argo2008 eddy survey. However, further support comes from dynamical considerations. A proxy for the coherence of an eddy, which also indicates the isolation of the eddy core, is the ratio $(\alpha)$ of swirl velocity to translation speed (e.g. Chelton et al., 2011b; Chaigneau et al., 2009). For the anticyclonic-modewater eddies (CVOO2007, CVOO2010) we have direct velocity observations, and just below the mixed-layer base they show a maximum $\alpha>9$ and a clear indication of the coherence of this part of these anticyclonic-modewater eddies.

For the Argo2008 survey of the cyclonic eddy, no direct swirl velocity observation exists, and as such $\alpha$ cannot be calculated. However, we used float profiles recorded before and after the float entered (May/June 2008) and left (March/April 2009) the eddy, and observed a fundamental change in the velocity shear profile - from a rotation with nearly constant velocity from just below the mixed layer ( $30 \mathrm{~m}$ ) to $400 \mathrm{~m}$ depth (maximum observation depth) at the beginning of the survey to a profile with a distinct peak in 
swirl velocity at about $110 \mathrm{~m}$ depth at the end of the float survey. Such a change in the flow structure indicates that the maximum $\alpha$ moved to deeper levels. We can only speculate that this vertical movement of maximum $\alpha$ and associated local decrease in $\alpha$ allowed surrounding waters to enter the eddy core and ended the isolation (Fig. 4).

\section{Conclusions}

Dead zones are observed in the open tropical North Atlantic at shallow depth, just below the mixed layer. The dead zones are generated in either cyclonic or anticyclonicmodewater eddies. Tracking of the eddies reveals them to be generated off the northwestern African coast. They propagate westward, with a speed of about $4.5 \mathrm{~km} \mathrm{day}^{-1}$ into the open ocean. We find, from direct observations of respiration within one cyclonic eddy, a 3- to 5-fold elevated aOUR profile when compared with the typical rates reported for the thermocline waters. High respiration rates were also found in anticyclonic-modewater eddies, but from measurements at one single depth only. From the few observations available, it seems that anticyclonic-modewater eddies may create more intense dead zones (DO close to zero) when compared with those in cyclonic eddies. This is possibly related to higher productivity in connection with the eddy-wind interaction or other mechanisms (Martin and Richards, 2001; McGillicuddy et al., 2007; Chelton et al., 2011a; Gaube et al., 2014). Moreover, the mixed-layer depth in anticyclonicmodewater eddies is very shallow, only a few tens of metres; as such nutrients from below will be lifted far up into the euphotic zone.

There is clearly a local impact of dead zone eddies on the ecosystem. During the passage of the anticyclonicmodewater eddies at the CVOO, we observed, in the target strength data from moored ADCPs, that acoustic backscatterers, such as zooplankters, stopped their diurnal migration cycle (Fig. 7). Such absence of vertical migration is indicative of zooplankters in the major OMZ regions (Ayon et al., 2008). While in the open ocean mobile organisms may escape from the dead zone, other organisms, such as the wide range of prokaryotes, may need to adapt to the environment in order to survive. In that sense the dead zone eddies can be seen as gigantic natural laboratories where an extreme environment is created in a relatively short period of time (a few months). These features may open new ways in investigating the adaptation techniques of organisms to survive low-DO environments.

In principle, open ocean dead zones in cyclonic and anticyclonic-modewater eddies could be created in all oceanic regions. Sufficient productivity, and particle sinking and remineralization, as well as non-linearity (and thus isolation) of the eddies, must be ensured for long enough periods of time. One other important control parameter is presumably the initial DO concentration. At the West African

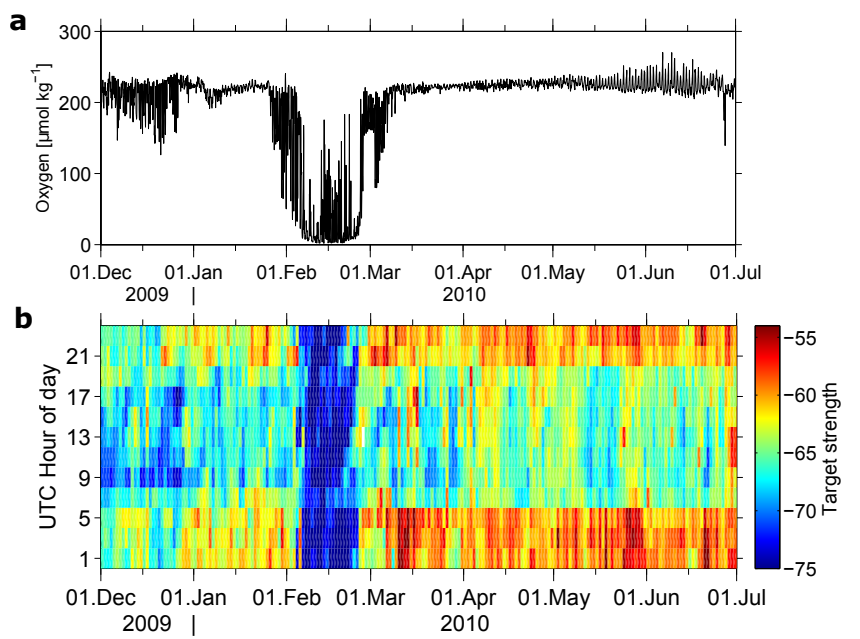

Figure 7. Time series of (a) oxygen at nominal $42 \mathrm{~m}$ depth and (b) relative target strength between 65 and $70 \mathrm{~m}$ depth against hours of the day (in dB). Target strength was calculated from the $300 \mathrm{kHz}$ acoustic Doppler current profiler data at CVOO. Minimal target strength during all hours of the day is seen during the passage of the low-DO anticyclonic-modewater eddy between 8 and 25 February 2010 .

coast, where we report here the eddies are created, DO concentrations are around 40 to $70 \mu \mathrm{mol} \mathrm{kg}^{-1}$ in the depth level that will later be occupied by low-DO waters. However, in the Pacific or the Indian Ocean, coastal DO concentrations are lower and extremes in other biogeochemical parameters may be generated. Here, anomalous nitrogen isotope compositions (Altabet et al., 2012) or anomalous phytoplankton distributions (Morales et al., 2012) have been reported to exist in anticyclonic-modewater eddies in the past.

In order to detect dead zone eddies from space, via SLA data, concurrent in situ observations of the vertical structure of the water column are required. A combination of Argo float data and SLA data is a promising technique that has been already applied regionally (southeastern Pacific; Chaigneau et al., 2009) and globally (Zhang et al., 2013) but without a focus on detecting anticyclonic-modewater eddies or water mass anomalies in general. We did a preliminary analysis for the North Atlantic OMZ region, using SLA data and Argo float data, that revealed about $10 \%$ of the anticyclones are anticyclonic-modewater eddies (Florian Schütte, personal communication). However, information about the oxygen distribution would still be required to quantify the impact of the dead zone eddies on the large-scale oxygen budget.

Eddies were observed less than $100 \mathrm{~km}$ north of the Cabo Verde islands; thus a possible interaction of a dead zone eddy with an island must be considered. Given the shallow depth of a few tens of metres where lowest DO concentrations are found, a sudden flooding of a coastal areas with low-DO waters may occur. A dramatic impact on the local ecosys- 
tems and sudden fish or crustacean death may be the consequence. In retrospect, such eddy-island interactions may explain events that have been reported in the past (O. Melicio, personal communication, National Fisheries Institute INDP, Mindelo, São Vicente, Cabo Verde).

One may wonder why dead zone eddies have not been discovered before. Besides possible undersampling issues for the tropical eastern North Atlantic in the past, it is likely that such low DO concentrations were disregarded as "outliers" in the data sets. In fact, we first interpreted the low DO at CVOO2007 as an outlier related to an instrumental error, and only the more recent events recorded with the double-sensor package at CVOO2010, combined with sophisticated optode calibration procedures, gave us confidence that our observations were real.

Acknowledgements. Financial support is acknowledged from the European Commission for FP7 projects GROOM (284321), CARBOOCEAN (264879), CARBOCHANGE (264879) and FixO3 (312463); from the DFG for Collaborative Research Centre "SFB 754"; from the BMBF for SOPRAN (03F0462A); and from AWA (01DG12073E). CVOO is part of the OceanSITES network. SLA data were produced by Ssalto/Duacs and distributed by Aviso (www.aviso.oceanobs.com). MyOcean products were used. Argo float data are available from the Coriolis data centre (www.coriolis.eu.org). Comments from the two anonymous reviewers very much improved the quality of the manuscript's presentation. We also thank Alice Pietri for stimulating discussions on sub-mesoscale dynamics and Andreas Oschlies for comments on an earlier version of the manuscript.

Edited by: M. Grégoire

\section{References}

Alldredge, A. L. and Cohen, Y.: Can microscale chemical patches persist in the sea?, Microelectrode study of marine snow, fecal pellets, Science, 235, 689-691, 1987.

Altabet, M. A., Ryabenko, E., Stramma, L., Wallace, D. W. R., Frank, M., Grasse, P., and Lavik, G.: An eddy-stimulated hotspot for fixed nitrogen-loss from the Peru oxygen minimum zone, Biogeosciences, 9, 4897-4908, doi:10.5194/bg-9-48972012, 2012.

Armi, L. and Zenk, W.: Large Lenses of Highly Saline Mediterranean Water, J. Phys. Oceanogr., 14, 1560-1576, 1984.

Ayon, P., Criales-Hernandez, M. I., Schwamborn, R., and Hirche, H.-J.: Zooplankton research off Peru: a review, Prog. Oceanog., 79, 238-255, 2008.

Brandt, P., Bange, H. W., Banyte, D., Dengler, M., Didwischus, S.-H., Fischer, T., Greatbatch, R. J., Hahn, J., Kanzow, T., Karstensen, J., Körtzinger, A., Krahmann, G., Schmidtko, S., Stramma, L., Tanhua, T., and Visbeck, M.: On the role of circulation and mixing in the ventilation of oxygen minimum zones with a focus on the eastern tropical North Atlantic, Biogeosciences, 12, 489-512, doi:10.5194/bg-12-489-2015, 2015.
Chaigneau, A., Eldin, G., and Dewitte, B.: Eddy activity in the four major upwelling systems from satellite altimetry (1992-2007), Prog. Oceanogr., 83, 117-123, 2009.

Chaigneau, A., Le Texier, M., Eldin, G., Grados, C., and Pizarro, O.: Vertical structure of mesoscale eddies in the eastern South Pacific Ocean: a composite analysis from altimetry and Argo profiling floats, J. Geophys. Res., 116, C11025, doi:10.1029/2011JC007134, 2011.

Chelton, D., Schlax, M., Samelson, R., and de Szoeke, R. A.: Global observations of large oceanic eddies, Geophys. Res. Lett., 34, L15606, doi:10.1029/2007GL030812, 2007.

Chelton, D. B., Gaube, P., Schlax, M. G., Early, J. J., and Samelson, R. M.: The Influence of Nonlinear Mesoscale Eddies on NearSurface Oceanic Chlorophyll, Science, 334, 328-332, 2011 a.

Chelton, D. B., Schlax, M. G., and Samelson, R. M.: Global observations of nonlinear mesoscale eddies, Prog. Oceanogr., 91, 167-216, $2011 \mathrm{~b}$.

Diaz, R. J. and Rosenberg, R.: Spreading dead zones and consequences for marine ecosystems, Science, 321, 926-929, 2008.

d'Ovidio, F., Monte, S. D., Penna, A. D., and Guinet, C. C. C.: Ecological implications of eddy retention in the open ocean: a Lagrangian approach, J. Phys. A, 46, 254023, doi:10.1088/17518113/46/25/254023, 2013.

Eden, C. and Dietze, H.: Effects of mesoscale eddy/wind interactions on biological new production and eddy kinetic energy, J. Geophys. Res., 114, C05023, doi:10.1029/2008JC005129,2009.

Garcia, H. and Gordon, L.: Oxygen solubility in seawater: Better fitting equations, Limnol. Oceanogr., 37, 1307-1312, 1992.

Gaube, P., McGillicuddy, D. J., Chelton, D. B., Behrenfeld, M. J., and Strutton, P. G.: Regional variations in the influence of mesoscale eddies on near-surface chlorophyll, Geophys. Res., 119, 8195-8220, 2014.

Hahn, J., Brandt, P., Greatbatch, R., Krahmann, G., and Körtzinger, A.: Oxygen variance and meridional oxygen supply in the Tropical North East Atlantic oxygen minimum zone, Clim. Dynam., 43, 2999-3024, 2014.

Jenkins, W. J.: Oxygen utilization rates in North Atlantic subtropical gyre and primary production in oligotrophic systems, Nature, 300, 246-248, 1982.

Kalvelage, T., Jensen, M. M., Contreras, S., Revsbech, N. P., Lam, P., Günter, M., LaRoche, J., Lavik, G., and Kuypers, M. M. M.: Oxygen sensitivity of anammox and coupled N-cycle processes in oxygen minimum zones, PLoS ONE, 6, e29299, doi:10.1371/journal.pone.0029299, 2011.

Karstensen, J., Stramma, L., and Visbeck, M.: Oxygen minimum zones in the eastern tropical Atlantic and Pacific oceans, Prog. Oceanogr., 77, 331-350, 2008.

Klein, P. and Lapeyre, G.: The oceanic vertical pump induced by mesoscale and submesoscale turbulence, Ann. Rev. Mar. Sci., 1, 351-375, 2009.

Kostianoy, A. and Belkin, I.: A survey of observations on intrathermocline eddies in the world ocean, in: Mesoscale/Synoptic Coherent Structures in Geophysical Turbulence, edited by: Nihoul, J. and Jamart, B., vol. 50, Elsevier, New York, 821-841, 1989.

Lévy, M., Ferrari, R., Franks, P. J. S., Martin, A. P., and Rivière, P.: Bringing physics to life at the submesoscale, Geophys. Res. Lett., 39, L14602, doi:10.1029/2012GL052756, 2012. 
Luyten, J., Pedlosky, J., and Stommel, H.: The ventilated thermocline, J. Phys. Oceanogr., 13, 292-309, 1983.

Mahadevan, A., Thomas, L. N., and Tandon, A.: Comment on "Eddy/wind interactions stimulate extraordinary mid-ocean plankton blooms", Science, 320, p. 448, doi:10.1126/science.1152111, 2008.

Martin, A. and Richards, K.: Mechanisms for vertical nutrient transport within a North Atlantic mesoscale eddy, Deep-Sea Res., 48, 757-773, 2001.

McGillicuddy, D. J., Anderson, L. A., Bates, N. R., Bibby, T., Buesseler, K. O., Carlson, C. A., Davis, C. S., Ewart, C., Falkowski, P. G., Goldthwait, S. A., Hansell, D. A., Jenkins, W. J., Johnson, R., Kosnyrev, V. K., Ledwell, J. R., Li, Q. P., Siegel, D. A., and Steinberg, D. K.: Eddy/wind interactions stimulate extraordinary mid-ocean plankton blooms, Science, 316, 1021-1026, 2007.

Morales, C. E., Hormazabal, S., Correa-Ramirez, M., Pizarro, O., Silva, N., Fernandez, C., Anabalon, V., and Torreblanca, M. L.: Mesoscale variability and nutrient-phytoplankton distributions off central-southern Chile during the upwelling season: The influence of mesoscale eddies, Prog. Oceanog., 104, 17-29, 2012.

Okubo, A.: Horizontal dispersion of floatable particles in the vicinity of velocity singularity such as convergences, Deep-Sea Res., 17, 445-454, 1970.

Pascual, A., Faugere, Y., Larnicol, G., and Le Traon, P.-Y.: Improved description of the ocean mesoscale variability by combining four satellite altimeters, Geophys. Res. Lett., 33, L02611, doi:10.1029/2005GL024633, 2006.

Pascual, A., Ruiz, S., Buongiorno Nardelli, B., Guinehut, S., Iudicone, D., and Tintore, J.: Net primary production in the Gulf Stream sustained by quasi-geostrophic vertical exchanges, Geophys. Res. Lett., 42, 441-449, 2015.
Risien, C. M. and Chelton, D. B.: A Global Climatology of Surface Wind and Wind Stress Fields from Eight Years of QuikSCAT Scatterometer Data, J. Phys. Oceanogr., 38, 2379-2413, 2008.

Sangrà, P., Pascual, A., Rodríguez-Santana, Á., Machín, F., Mason, E., McWilliams, J. C., Pelegrí, J. L., Dong, C., Rubio, A., Arístegui, J., Marrero-Díaz, Á., Hernández-Guerra, A., Martínez-Marrero, A., and Auladell, M.: The Canary Eddy Corridor: A major pathway for long-lived eddies in the subtropical North Atlantic, Deep-Sea Res. Pt. I, 56, 2100-2114, 2009.

Souza, J. M. A. C., de Boyer Montegut, C., and Le Traon, P.-Y.: Comparison between three implementations of automatic identification algorithms for the quantification and characterization of mesoscale eddies in the South Atlantic Ocean, 7, 317-334, 2011.

Stramma, L., Visbeck, M., Brandt, P., Tanhua, T., and Wallace, D.: Deoxygenation in the oxygen minimum zone of the eastern tropical North Atlantic, Geophys. Res. Let., 36, 9248276, doi:10.1029/2009GL039593, 2009.

Tengberg, A., Hovdenes, J., Andersson, H., Brocandel, O., Diaz, R., Herbert, D., Arnerich, T., Huber, C., Kortzinger, A., Khripounoff, A., Rey, F., Rönning, C., Schimanski, J., Sommer, S., and Stangelmayer, A.: Evaluation of a lifetime-based optode to measure oxygen in aquatic systems, Limnol. Oceanogr., 4, 7-17, 2006.

Vaquer-Sunyer, R. and Duarte, C. M.: Thresholds of hypoxia for marine biodiversity, P. Natl. Acad. Sci. USA, 105, 15452-15457, 2008.

Wilding, J.: The oxygen threshold for three species of fish, Ecology, 20, 253-263, 1939.

Wright, J. J., Konwar, K. M., and Hallam, S. J.: Microbial ecology of expanding oxygen minimum zones, Nature Rev. Microbiol., 10, 381-394, 2012.

Zhang, Z., Zhang, Y., Wang, W., and Huang, R. X.: Universal structure of mesoscale eddies in the ocean, Geophys. Res. Lett., 40, 3677-3681, 2013. 